\title{
ALEXANDER OF APHRODISIAS ON SYLLOGISTIC REASONING
}

\author{
SERGEI GARIN \\ Kuban State University \\ Centre for the study and promotion of the Ancient Greek \\ intellectual heritage " $\Delta\llcorner\alpha \lambda \varepsilon \varkappa \tau i x \eta n "$ \\ svgarin@gmail.com
}

\begin{abstract}
The article deals with ancient ideas on the nature of syllogistics on the example of Empire's official Peripatetic philosopher, Alexander of Aphrodisias. We interpret Alexander's position on the syllogistic form as a theory of constant function. Alexander offers a conjunctive and purely formal understanding of the nature of syllogistic necessity. This approach to the modal properties of assertoric judgments differs from Theophrastus' ontological position, who believed that modal characteristics of assertoric premises are determined by looking to the state-of-affairs to which they refer. Also the paper examines Theophrastus' legacy of hypothetical syllogisms related to Alexander. Stoic and Peripatetic versions are also compared against the background of Alexander's logical amalgamation. The article elucidates late "Peripatetic conservatism" regarding the hypothetical syllogistics. We discuss the syntax of propositional / term relations (ei to A, to $B$ ), tackling the problem of grammatical ellipsis.

KEYWORDS: History of logic, Alexander of Aphrodisias, Theophrastus, Galen, categorical syllogism, Stoics, ellipsis.

* This research is supported by the PIRSES GA / 2013612 research grant, Göttingen, Germany.
\end{abstract}

\section{Introduction}

The importance of Alexander of Aphrodisias' logical ideas related to the fact that his "defence" of logic, which has become a part of a larger commentary on Aristotle's "Analytics" and "Topics," was devised at a time when logical matters were neglected, both in education and science. ${ }^{1}$ For the Peripatetic school, beyond any doubt, Alexander was a comprehensive figure, deploying systematic arguments in defence of apodictic $\varepsilon \pi\left\llcorner\tau \eta^{\prime} \mu \eta\right.$, as in matters of science, knowledge, and in the

\footnotetext{
${ }^{1}$ Todd 1976, 17. See also Barnes, Bobzien, Flannery, Ierodiakonou 2014, 46. 
field of ethics, moral decisions, religion and broad social practice. ${ }^{2}$ However, up to now Alexander's logical legacy has been scantily explored. As Luca Gill pointed out, "Alexander has been rediscovered during recent decades; however, his logical thought has been in some sense neglected." ${ }^{33}$ As we believe, the significance of his logic goes beyond Peripatetic $\sigma \times 0 \lambda \hat{\eta}$, since Alexander combines and transforms key logical techniques of Late Antiquity in his own way.

Alexander starts with a definition of logic ${ }^{4}$, setting it up as a syllogistic study

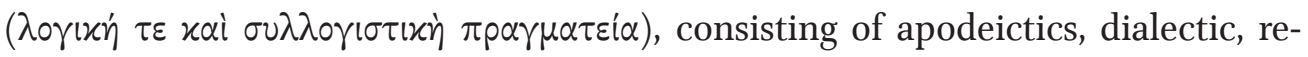

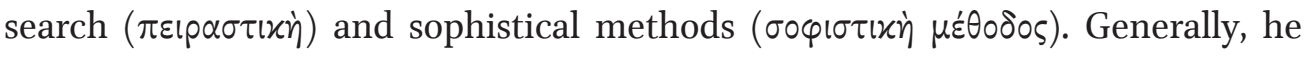
understands logic as a kind of philosophical knowledge. However, other

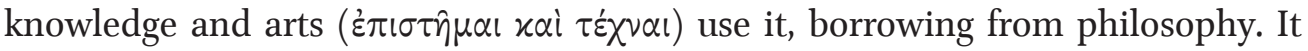
should be noted that at the time of Alexander, logical syllogistics had already included a wide arsenal of demonstrative reasoning. There were assertoric and modal syllogisms, hypothetical Theophrastus' (Eudemus') syllogisms, disjunctive syllogisms, elements of propositional logic and predication theory. According to some Arabic sources, ${ }^{5}$ perhaps as early as Alexander's time (2nd century AD), it was widely accepted that conditional hypothetical syllogisms drew up important parts of valid deduction schema available in philosophical debate.

\section{$\Sigma \cup \zeta \breve{\gamma} \gamma_{i} \alpha$ and conjunctive nature of syllogistic necessity}

The study of the deductive nature of logic in Late Antiquity appears to be very problematic. ${ }^{6}$ It is notorious that Aristotle himself understood deduction quite

\footnotetext{
${ }^{2}$ One of the few works considering Alexander's thought entirely is Sharples 1987. It is worth mentioning the work on some aspects of Alexander's logic, including the Aristotelian method of proof ( $\left.\varepsilon^{\prime} x \theta \varepsilon \sigma / \varsigma\right)$, Flannery 1995. Alexander's modal syllogistics are analyzed in Luca Gili's 2015 work.

${ }^{3}$ Gili 2015, 1.

${ }^{4}$ To begin with, Alexander discuses different views on logic within the general, so to speak, philosophical framework. We omit the full-scale ancient discussion on the role of logic for philosophy, noting only a few details. Thus, as Alexander presents it, some ancient authors ( $\alpha p \chi \alpha i o l)$ expressed the view that logic is useful as an instrument or tool and useless as a full-fledged part of philosophy. Alexander believes that if logic is needed as some sort of training for finding and discovering truths, we have the instrumental aspect of logical knowledge. If logic studies its inner laws / truths, it acts as a part of philosophy. Thus, Alexander considers the criteria for the use of logic outside or inside the logic itself. Mind training function for discoveries and training guidance for thinking

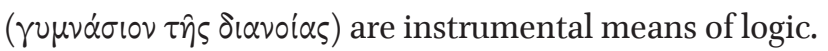

${ }^{5}$ Karimullah 2014, 214.

${ }^{6}$ See Flannery 1995, 109.
} 
differently. ${ }^{7}$ Even in our time, A.N. Prior considers the problem of logical form as arduous to define: "The term 'form' ... is not an easy one to define, but it is easy enough to illustrate." ${ }^{8}$ Some authors reduce the concept of syllogism simply to bare deduction. ${ }^{9}$

In his commentary on Aristotle's "Prior Analytics," Alexander develops Peripatetic logical argumentation, designed to resolve a lot of issues circulated in the 2nd century AD. The standard set of late Peripatetic logical issues includes several introductory questions: first, what is the relationship between logical structures of reasoning and what is very vaguely called content? Secondly, what is the basis for the logical inference - terms or propositions? The last question is related to the two competing paradigms in ancient syllogistics - term and sentence logics.

Considering the first question, it is obvious that Alexander, being a Peripatetic, although in very eclectic times, quite definitely distinguished logical form and content. Although Barnes called Alexander's position on this issue "not always coherent," albeit adding that "the ancients were in this respect no worse off than most moderns". ${ }^{10}$ Alexander puts form and content problem in the general Peripatetic framework. The definition of syllogism, as the main method in Alexander's logic, is characterized by the term matrix, or scheme:

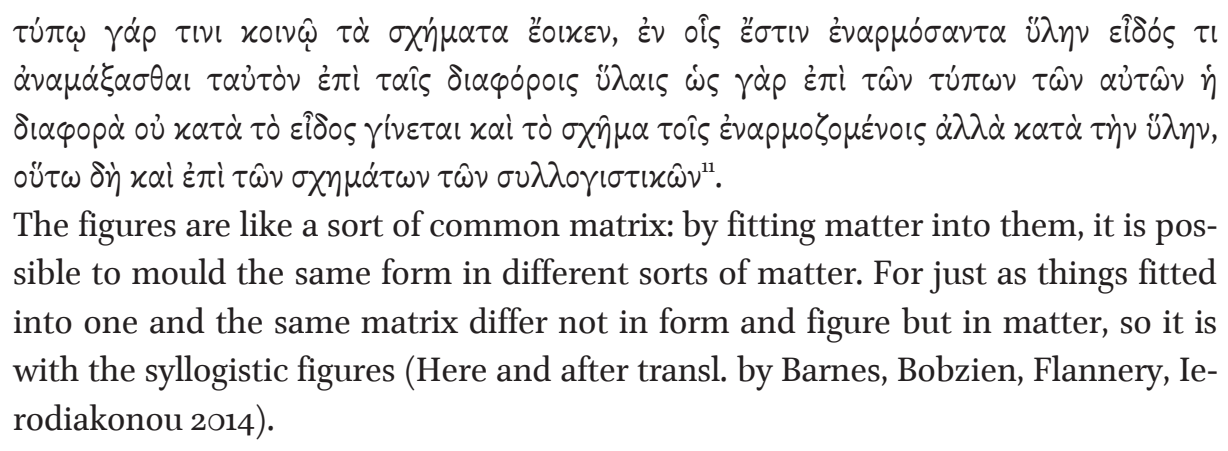

Here, obviously, Alexander follows Aristotelian terminological tradition. However, Alexander adds a distinctive feature of constant temporal function for any valid syllogism:

\footnotetext{
${ }^{7}$ Malink 2015, 267

${ }^{8}$ Flannery 1995, 110.

${ }^{9}$ See Malink 2015, 267. Identifying syllogism with deduction, we, obviously use fuzzy concepts, since, indeed, every syllogism belongs to deduction, but the reverse is not true. The concepts of deduction and syllogism, considered as sets in set theory, are not equipotent.

${ }^{10}$ Barnes 2012, 73 .

${ }^{11}$ in A.Pr. 1, 6.1. See also Alexander's works in A.Pr.52.19-25, in Top. 2.9-15.
} 


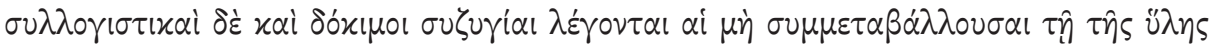

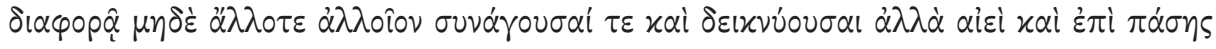

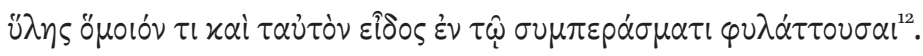

Combinations are called syllogistic and reliable if they do not alter together with differences in the matter - i.e. if they do not deduce and prove different things at different times, but always and in every material instance, preserve one and the same form in the conclusion (transl. by Barnes, Bobzien, Flannery, Ierodiakonou).

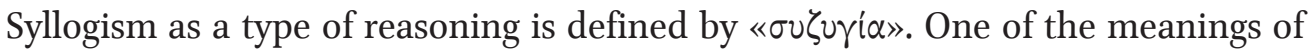
this term, besides "conjugation", is conjunction, i.e. syllogism is the conjunction of elements. On the whole, according to Alexander, the difference in matter (con-

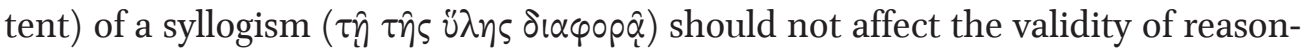

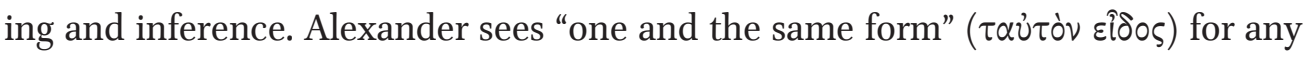

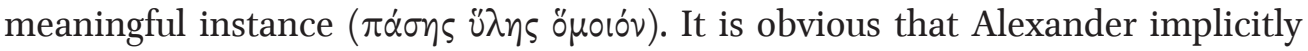
develops a functional definition of form and content because he treats form as a function that has the same value for any incoming argument. Matter of a syllogism acts similarly to the argument of a function. Alexander sees the merit of logical form precisely in the stability and reliability of inference. The effect of a syllogism is determined by two parameters:

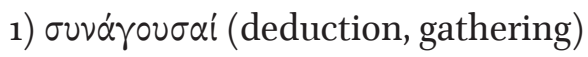

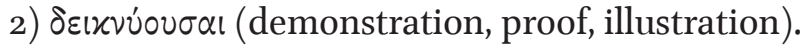

One of the intrinsic features of syllogistic inference is indicated by the adjective

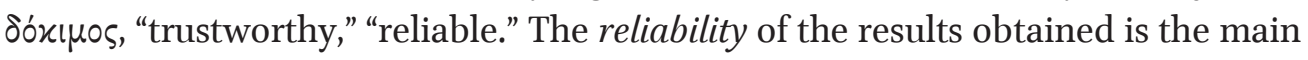
difference between logic and vague ordinary knowledge.

We may say that the conclusion of a syllogism has a constant function, which is applied to the input content. Thus, Alexander sees valid syllogism as a certain constant function whose output value is the same for every input value. It receives the same value for $f(x)$, no matter what $x$ is. ${ }^{13}$ Conversely, if the output value varies depending on input matter, then this type of reasoning, according to the philosopher form Aphrodisia, is not reliable and, consequently, does not belong to the apodictic structures of logic and, therefore, is not a genuine syllogism.

Alexander uses a specific notion of change describing unreliable syllogistic structures. Therefore, it is possible to describe the types of a syllogism in Alexander in the following way:

\footnotetext{
${ }^{12}$ in A.Pr. $4.3,5^{2}$.

${ }^{13}$ To paraphrase J. Hintikka, we may say that Alexander's approach is a theory of certain independence of inference from incoming data.
} 
1) $f(\mathrm{x})=$ const where $\mathrm{x}$ - matter

Working logical syllogism, reliable.

2) $f(\mathrm{x})=$ non-const where $\mathrm{x}$ - matter

Non-working, non-logical syllogism, not reliable.

However, the question arises, how may the function for any incoming argument have the same value? In propositional calculus, using Boolean functions, one can construct always-true formulas, or logical tautologies. A classic example is modus ponens (MP).

$$
M P:((p \rightarrow q) \wedge p) \rightarrow q
$$

For comparison, consider the weakened mode, inversed modus ponens (IMP):

$$
I M P:((p \rightarrow q) \wedge q) \rightarrow p
$$

which receives a different output value due to the different values of incoming arguments. The difference between $M P$ and weakened IMP, in terms of Alexander, is that the former does not change over time, i.e. produces only stable constant output (true =1), while the latter takes different values depending on incoming arguments:

Whereas

$$
\begin{aligned}
& f(\mathrm{x}),=\text { const } \\
& f-M P
\end{aligned}
$$

$$
\begin{aligned}
& f(\mathrm{x}),=\text { non-const } \\
& f-I M P .
\end{aligned}
$$

In Fregean terms, Alexander's syllogism is a functional expression. If we consider any of the incorrect modes of categorical or hypothetical syllogism, we may see that they have different output values (sometimes, however, true) for different input values. For example, the modus Cesare (EAE-2) of the second figure of the syllogism, considered as a function, has an always-true conclusion, while the modus AAA-2 is volatile, i.e. truthfulness and falsehood of the output depend on input values of the premises. Stability of inference, generally, is the intrinsic feature of Alexander's account on syllogistic epistemology.

Conversely, Alexander understands the nature of non-demonstrative syllo- 
gisms based on their instability over time. ${ }^{14}$ Thus, he considers a non-logical system of inference when the conclusion varies depending on the initial values of the premises:

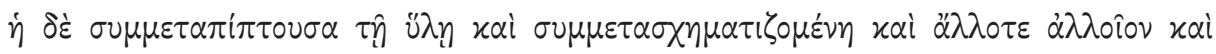

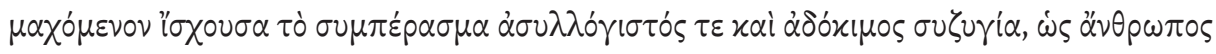

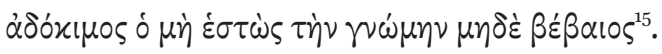

Combinations which change and alter configuration together with the matter and acquire different and conflicting conclusions at different times are non-syllogistic and unreliable just as a man is unreliable if he is not stable and firm in his judgment (transl. by Barnes, Bobzien, Flannery, Ierodiakonou).

Thus, we see a framework employing temporal aspects for analysing logical necessity. The definition of the logical validity of syllogistic inference is based on stability over time and stability of syllogistic truth function is the basis for Alexander's demarcation between reliable and unreliable knowledge.

Alexander's understanding of the nature of syllogistic reasoning becomes clearer in his modal theory where he puts forward polemic argument against Theophrastus. ${ }^{16}$ He claims that propositions have necessity ( $\left.\tau \dot{0} \dot{\alpha} v \alpha \gamma x \alpha \hat{\imath} 0 v\right)$, actual-

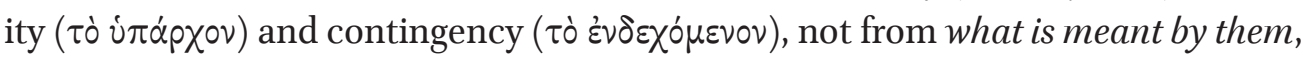

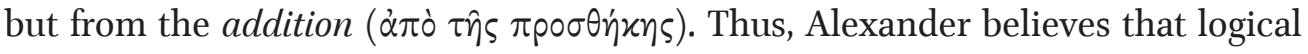
necessity is not determined by matter of a syllogism, but only by the very combination of certain parts of the syllogism into one apodictic whole. Logical necessity, in this case, is not of an actual nature but a property of logical connection. In this sense, we may say that he is inclined to the syntactic theory of logical necessity. This approach to the modal properties of assertoric judgments is different from Theophrastus, who believed that the modal characteristics of assertoric premise is determined by observing the state-of-affairs to which it refers. ${ }^{17}$ Any non-Aristotelian tradition in Peripatetic logic can be probably traced to Theophrastus.

\section{Theophrastus' legacy: Peripatetic / Stoic amalgamation and hypothetical syllogism}

As it is known, in Late Antiquity there were at least two logics: categorical and hypothetical syllogistics. However, Alexander's viewpoint regarding propositional logic is not completely clear. Obviously, he knew hypothetical propositional logic

\footnotetext{
${ }^{14}$ General study of temporal aspects within the framework of Peripatetic doctrine of necessity can be found in Hintikka 1973.

${ }^{15}$ In A.Pr.1.52.

${ }^{16}$ See Flannery 1995, 111.

${ }^{17}$ Ibid.
} 


\section{$38 \quad$ Alexander of Aphrodisias on syllogistic reasoning}

perfectly since he mentions ancient Peripatetics who studied mixed syllogisms.

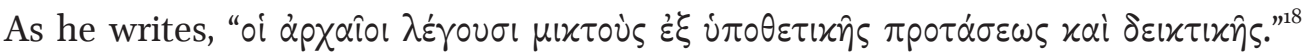
(As suggested by S. Bobzien, in this passage, Alexander refers to the preceding Peripatetic authors ( $\dot{\alpha} p \chi \alpha \hat{i} \iota)$ ), which is his usual way of referring to the earlier Peripatetics. ${ }^{19}$ Alexander does not mention any of the early Peripatetic philosophers by name, except for Theophrastus; apparently, this gives us reason to conclude that Theophrastus, in fact, developed a detailed theory of non-Aristotelian propositional logic. ${ }^{20}$ Alexander knows various propositional techniques by his time, and at least he could distinguish the teachings of ancient Peripatetics from Stoic

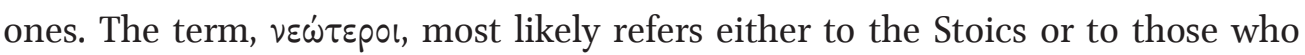
accept Stoic logical views.

If we consider the canonical Stoic system of propositional syllogism, as suggested by Bobzien, ${ }^{21}$ there will be the following scheme:

$\begin{array}{lll} & \text { If } F \mathrm{a}, \mathrm{Ga} & \text { hypothetical protasis } \\ \text { Hypothetical } & \text { But } F \mathrm{a} & \text { probative protasis } \\ & \text { Therefore } G \mathrm{a} & \text { the original demonstrandum }\end{array}$

Either $\mathrm{Fa}$ or $\mathrm{Ga} \quad$ hypothetical protasis

Disjunctive But not $\mathrm{Fa} \quad$ probative protasis

Therefore $\mathrm{Ga}$ the original demonstrandum

But as far as Alexander's scheme originated from a later time, this could be its supposed logical structure:

$\begin{array}{ll} & \text { For all } \mathrm{x}: \text { if } G \mathrm{x}, \\ \text { Hypothetical } & F \mathrm{x} \\ & \text { But } G \mathrm{a} \\ & \text { Therefore Fa } \\ & \text { Either } F \mathrm{a} \text { or } G \mathrm{a} \\ \text { Disjunctive } & \text { But not } F \mathrm{a} \\ & \text { Therefore } G a\end{array}$

\footnotetext{
${ }^{18}$ In APr. 262.31-2.

${ }^{19}$ Bobzien 2002, 381 .

${ }^{20}$ Ibid.

${ }^{21}$ Bobzien 2002, 381 .
} 
This is a commonplace that Peripatetics are mainly associated with categorical syllogistic. In general, in late Peripatetic logic, one can regret that Aristotle did not develop any theory of hypothetical syllogisms. ${ }^{22}$ However, some Peripatetics, following Aristotle, believed that their categorical syllogistic covers all types of valid logical reasoning. ${ }^{23}$ The Stoics, in turn, adhered to the same for their propositional logic. These two systems considered themselves to be competitors, and behind the texts, there was a hot philosophical debate between "term" and "sentence" logics.

Barnes believes that Theophrastus is a representative of categorical logic with a slight inclination to propositional theory. ${ }^{24}$ There is a reason to suppose that Peripatetic logic in the Hellenistic period is mainly connected with the logical legacy of Theophrastus. Several texts show that Theophrastus discussed hypothetical syllogisms, thereby living up the promise made by Aristotle in A.Pr. ${ }^{0 \mathrm{Oa}}{ }^{25}$

At the time of Aristotle, conceptual neglect of propositional logic could be somehow explained by the fact that Peripatetic logic originated in Platonic $\sigma \times 0 \lambda \hat{\eta}$, often resorting to the procedure of deriving concepts from each other. Modus Barbara of the first figure is a clear illustration of the transitive relation from general to specific through the relationship between terms - from major, through the middle, to the minor one. Logic in the Academy had a significant inclination rather towards terms and their relations than to propositions. Plato's eidoi are designated by separate concepts but not by sentences. ${ }^{26}$

By the second and third centuries $\mathrm{AD}$, Stoic logic had already become lingua franca, along with Peripatetic syllogistics. The Peripatetic version of Stoic logic ascended to Theophrastus and his attempt to fill the gaps of Aristotelian logic. Theophrastus' legacy was reflected in the works of many commentators such as Simplicius, who considers logical inference in Theophrastus' works as implication. $^{27}$

It should be noted that by the time of Alexander, interest in propositional logic was very common among academics. Thus, Galen, the contemporary of Alexander, in Inst. Log. III. 3-5, reports that "the ancients" called conditional judg-

\footnotetext{
${ }^{22}$ Alexander, in A.Pr. 389. 31-390.1, Philoponus, in A.Pr. 242. 14-15, 359· 30-2, Ammonius, in A.Pr. $67 \cdot 35$.

${ }^{23}$ Alexander and Galen may be considered as prominent representatives of this posi-

${ }^{24}$ Barnes 1983, 279-83.

${ }^{25}$ On this point, see Barnes 1983, 28o-82.

${ }^{26}$ In this spirit, Plato's "Cratylus" can be considered as one of the earliest attempts to devise a semantic theory of terms based on etymology.

${ }^{27}$ Simp. Cael. 552.31-553.4
} tion. 
ments hypothetical based on the connection ( $(\alpha \tau \alpha \sigma v \nu \varepsilon \chi \varepsilon i \alpha \nu)$ and disjunctive statements ( $\kappa \alpha \tau \alpha \delta(\alpha \iota p \varepsilon \sigma \nu)$ ). It is noteworthy that Galen distinguishes categorical and hypothetical syllogisms as follows: categorical one is about the being of things

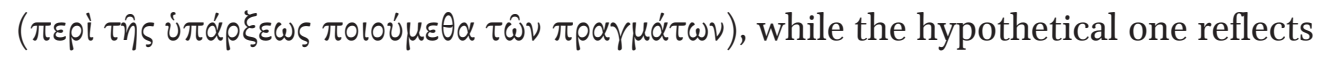
bare interrelations - "if there is a first, there must be the second one; if there is one, then no other. ${ }^{128}$ In Galen's view, categorical syllogism is related directly to ontology while hypothetical inference is based on pure propositional relations. Galen as well examines the conjunctive and disjunctive nature of hypothetical syllogisms.

Despite the differences of statuses - Galen wasn't a Peripatetic philosopher, while Alexander had the position of chief Imperial logician, probably the head of the Lyceum ${ }^{29}$ - both authors are close on a number of issues. In Galen, we also see that "the ancients" are opposed to "contemporaries," who use Stoic propositional logic. So, probably, Galen by "the ancients" similarly means Theophrastus and his heirs.

Theophrastus devised figures of hypothetical syllogisms, considering whollyhypothetical, categorical and disjunctive ones. In each figure, he systematically discussed valid, strong and weak modes, mainly concentrating on valid figures..$^{30}$ Alexander discusses Theophrastus' legacy of fully hypothetical syllogisms in the context of Peripatetic tradition. As Barnes pointed out, Alexander's principle is the following: "wholly hypothetical syllogisms are not genuine syllogisms. For they do not prove anything. They do not prove anything because their conditional conclusions do not assert anything; they do not say that anything holds or does not hold. They do not claim that something is holding or not holding. ${ }^{3^{1}}$

Obviously, Alexander's approach to hypothetical syllogisms is quite close to Galen's logic. They both agree that wholly-hypothetical syllogism is not a real syllogism because it is far from real ontology, not being able to determine whether something is the case or not. Alexander writes further in his commentary on the first book of Aristotle's "Prior Analytics":

${ }^{28}$ Galen, Inst. $\log \cdot 3 \cdot 1-5$.

${ }^{29}$ Among modern scholars, there is no consensus about where exactly Alexander taught. But, after the discovery in 2001 of the memorial stele at Karacasu, he erected in honour of his father in Aphrodisia, it is now clear that Alexander was the Head (diadochos) of the school in Athens. Whether it was a Lyceum or not is still unclear. This remarkable discovery is an addition to the only biographical evidence of Alexander, in De Fato, 164.3, addressed to Emperors Septimius Severus and Caracalla. See further Chaniotis 2004,79 .

$3^{30}$ Barnes 1983, 307.

${ }^{31}$ See Barnes 2012, 462 . 


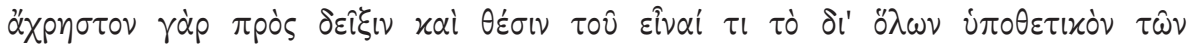

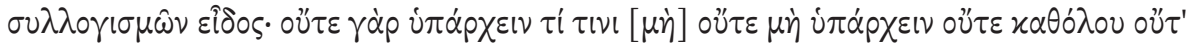

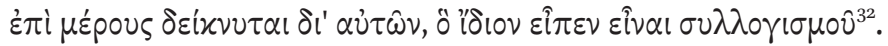

For the totally hypothetical form of syllogism is useless for proving and positing that something is the case, since it cannot be proved by means of them that something holds or does not hold of something either universally or particularly, which <Aristotle > says is the specific characteristic of a syllogism (transl. by I. Mueller)

According to Alexander, all hypothetical syllogisms are built over the categorical ones, being derivative by nature. The effectiveness of hypothetical reasoning is completely based on categorical statements connected, in turn, with the relation between terms:

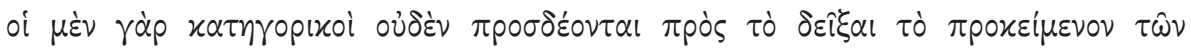

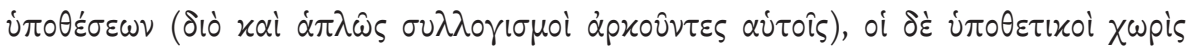

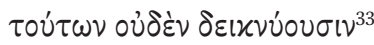

For categorical syllogisms do not need any additional hypothesis for proving what is proposed to be proved (and so, being self-sufficient, they are syllogisms without qualification), but hypothetical syllogisms prove nothing independently of categorical syllogisms (transl. by I. Mueller)

Thus, Alexander believes that conclusion of any syllogism should be a genuine statement, indicating that something is the case. Obviously, this approach is contrary to the modern propositional logic, where implication and equivalence are considered as genuine statements on the grounds that they claim something about reality.

Alexander does not explain the differences between a wholly hypothetical syllogism and a mixed one, such as modus ponens, but a later author, Philoponus defines fully hypothetical syllogism as consisting only of hypothetical statements. ${ }^{34}$ According to Philoponus, ${ }^{35}$ the concept of a "fully hypothetical syllogism" goes back to Theophrastus. Alexander reports that Theophrastus called such arguments of syllogisms by analogy ${ }^{36}$ on the grounds that the premises are similar to each other, and the conclusion is identical to the premises - they all show

\footnotetext{
${ }^{32}$ In A.Pr. 1. 265.

33 Ibid.

${ }^{34}$ In A.Pr. 243. 16, f. 302. 9-12.

${ }^{35}$ Ibid 302-9.

${ }^{36}$ In A.Pr. 326.9 .
} 
similarities. ${ }^{37}$ This remark, however, is not quite clear, since even in categorical syllogism, all premises and conclusions also have an analogous (categorical) structure.

Thus, Alexander, like Galen, knows well hypothetical syllogisms; however, considers them secondary and derivative from genuine categorical syllogisms. This point of view, obviously, we may call as peripatetic conservatism.

\section{Syntax of syllogistic inference and the problem of ellipsis}

Comparing scarce propositional elements in Alexander's works with Philoponus, and Boethius, we may notice some obvious discrepancies. In a recent debate among historians of logic, there has been a discussion about the syntax of such ancient expressions:

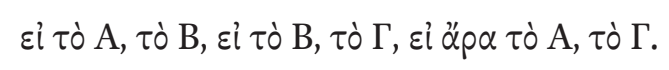

So, Alexander, Philoponus, and others use letters, but what do they mean? When late Peripatetics have the use of letters in hypothetical judgments, do they employ Stoic propositional nomenclature? It is obvious to assume that; indeed, the letters denote propositions, ${ }^{38}$ as is the case in modern propositional logic. However, other authors suggest that the letters might mean terms. ${ }^{39}$ Here is Alexander's text where he quotes Theophrastus and analyses the structure of hypothetical syllogism:

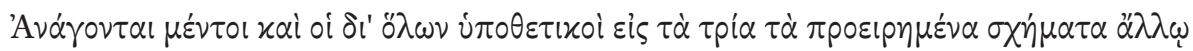

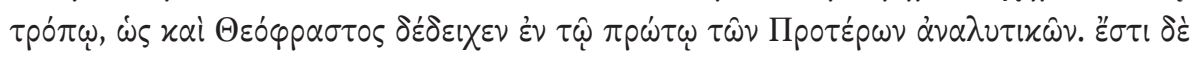

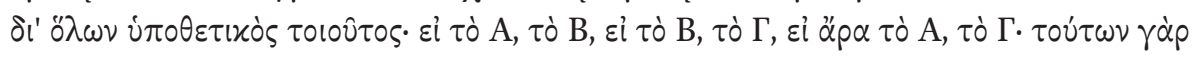

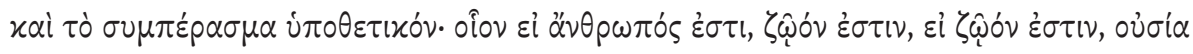

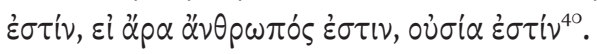

However, in fact, totally hypothetical < syllogisms $>$ are also reduced to the three previously described figures in another way, as Theophrastus also showed in the first book of his Prior Analytics. A totally hypothetical is like this: If A, B; if $B, \Gamma$; therefore, if $A, \Gamma$. The conclusion of these $<$ syllogisms $>$ is also hypothetical. Here is an example: If it is a human being, it is an animal; if it is an animal, it is a substance; therefore, if it is a human being, it is a substance (transl. by I. Mueller)

\footnotetext{
${ }^{37}$ 326.11-12. See also Barnes 2012, 442.

${ }^{38}$ Barnes 1983, 290.

${ }^{39}$ See, for example, Graeser 1973, 98-9.

${ }^{40}$ In A.Pr. 326.
} 
Alexander's approach, however, raises a number of questions. What is the syntactic status of the letters "A", "В", "Г"? Barnes believes that as far as it dictates by grammar, variables may only be propositions, similar to p's and q's in modern propositional calculus. No other substitution of "A" and "B" might create a correct grammatical meaning of the scheme "If A, then B." And we may suggest that Alexander indeed uses "A" and "B" as complete sentences.

Nevertheless, some scholars believe that Alexander's "А", "В", " $\Gamma$ " are letters, similar to Aristotle's logic, where they stand for universal terms such as "man," "animal, etc. For example, A. Graeser, analysing Theophrastus' logic, treats similar letters as variables for terms, rather than propositions. ${ }^{41}$ In this way, if "A" and "B" are letters for terms, we must explicitly refer to "If a man, then mortal." However, as Barnes suggested, in this case we have an incomplete, i.e. elliptical sentence. In general, the phenomenon of grammatical ellipsis was quite frequent in Ancient Greek. There are plenty of examples from "zero-copula" structures, found in-

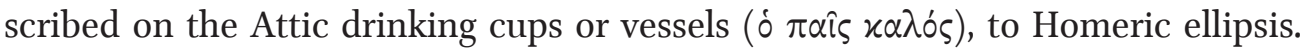
An example from Philoponus, where he explicitly considers variables as terms,

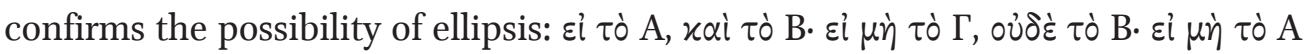

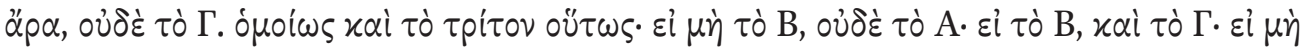
$\tau \dot{\partial} A \not \alpha p \alpha, ~ o v ่ \delta \dot{\varepsilon} \tau i \tau \hat{\omega} \nu \Gamma^{42}$. As Barnes suggests, the conclusion of the syllogism here ' $\Gamma$ " "can only be a term letter. But this may well betoken no more than a minor slip on Philoponus' part." 43 Thus, variables as terms make possible the simultaneous use of hypothetical propositional structures within Aristotle's syllogistics.

An important aspect also should be noted here. Aristotelian logic was characterized by relations between terms, indicating classes:

$$
\begin{aligned}
& A-B, \\
& B-\Gamma \\
& A-\Gamma
\end{aligned}
$$

The relation between terms in Aristotle's logic connected with categorical statements, where terms are subject $(\mathrm{S})$ and predicate $(\mathrm{P})$. The relation between $S$ and $P$ cannot be hypothetical / implicative. Stoic logic, contrariwise, is based on hypothetical sentential structures:

If $\mathrm{Fa}, \mathrm{Ga}$

But Fa

\footnotetext{
${ }^{41}$ Graeser 1973, 98.

${ }^{42}$ In A.Pr. 302.22

${ }^{43}$ Barnes 1983, 289.
} 
Therefore $G$ a

If we combine a hypothetical (implicative) structure with relations between terms, then it is neither Peripatetic, nor Stoic logic. In this Alexander's example, we have a structural amalgamation of the Peripatetic and Stoic nomenclatures:

\section{If $A$, then $B$ \\ If $B$, then $\Gamma$, \\ If $A$, then $\Gamma$,}

where the letters represent terms. Undoubtedly, such combination of two different logical traditions could only be possible by violation of grammar.

This amalgamation between Peripatetic and Stoic techniques in many ways originated in Alexander's works. ${ }^{44}$ As we know, Aristotle ignored hypothetical syllogisms, only cursorily mentioning them in "Analytics." As the Head of Aristotle's school in Athens, Alexander had to reconstruct that Peripatetic doctrine of hypothetical syllogisms, which could be; thus Alexander's theory was fairly subjunctive in nature. As A. Speca suggests: "the resuscitated version of hypothetical syllogistic that he presented in his commentary on the Prior Analytics is not what Aristotle in fact had in mind. It is rather a partial conflation of Peripatetic and Stoic logic." ${ }^{15}$ Speca believes that "Alexander failed to recognize crucial differences between hypothetical syllogistic and Stoic logic.... Largely because of this mistake, aspects of Peripatetic and Stoic logic have been partially confused for the past eighteen hundred years." ${ }^{146}$

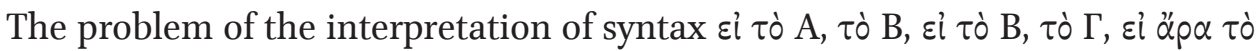
$\mathrm{A}, \tau \dot{o} \Gamma$ in the context of Peripatetic and Stoic logical nomenclatures may be elucidated by Boethius' treatise De hypotheticis syllogismis. As it is known, this treatise is the only surviving work in Greek or Latin on hypothetical syllogistics from Antiquity. K. Durr, in his remarkable study devoted to Boethius' "On hypothetical syllogisms", concluded that Boethius is substantially closer to Peripatetics than to Stoics. ${ }^{47}$ As pointed out by A. Speca, "now, mention of Aristotle, Theophrastus, and Eudemus, but not the Stoics, does indeed suggest that Boethius's sources

${ }^{44}$ Like Karl von Prantl accused Porphyry of poor understanding of the nature of categories, A. Speca considers Alexander guilty of unjustified mixing of different logical nomenclatures.

${ }^{45}$ Speca 2001, xii.

${ }^{46}$ Speca 2001, vi-vii

${ }^{47}$ Durr 1951, 11. 
were in the Peripatetic tradition and not the Stoic." ${ }^{48}$ Why is Boethius's opinion important for the purposes of our research? Because Boethius, chronologically standing at the very end of Late Antiquity, apparently calls A, B, $\Gamma$ as termini; and he regularly writes "est $A$ ", "est $B$ ", "est $C$ ", thus indicating beyond all doubt that he believes that "if A, then B" is elliptical and that "A" and "B" are terminal letters. ${ }^{49}$

In his noteworthy work, Barnes recognized at least four different interpretations of hypothetical syllogism: sentential, Philoponus' type, Boethius' type and the fourth one - Alexander of Aphrodisias.' The first two kinds are the following:

1) Sentential

$$
\begin{aligned}
& \text { If } \mathrm{P} \text {, then } \mathrm{Q} \text {, If } \mathrm{Q} \text {, then } \mathrm{R} \\
& \text { If } \mathrm{P} \text {, then } \mathrm{R} \text {. }
\end{aligned}
$$

2) Philoponian version:

$$
\begin{aligned}
& \text { If } a \text { is } F \text {, then } a \text { is } G \\
& \text { If } a \text { is } G \text {, then a is } H \\
& \text { If } a \text { is } F \text {, then } a \text { is } H^{50}
\end{aligned}
$$

The third version is based on Boethius' scheme. ${ }^{{ }^{1}}$ It's obvious that "The second and the fourth of these forms are special cases of the first. ${ }^{\prime 5^{2}}$

Thus, Theophrastus' legacy of hypothetical syllogism has several possible interpretations; which one to choose is a matter of preference and probably taste. However, by reducing all possible interpretations to alternative versions, we get,

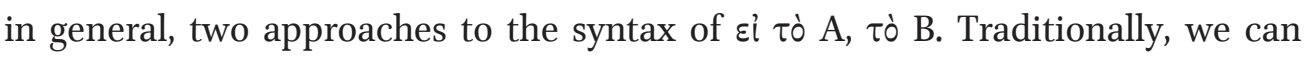
treat letters as propositional variables. In this case, they will be grammatically complete structures. Then the example of Theophrastus-Alexander will have the following form:

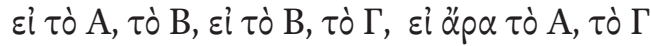

$$
\begin{aligned}
& ((\mathrm{p} \rightarrow \mathrm{q}) \wedge(\mathrm{q} \rightarrow \mathrm{s})) \rightarrow(\mathrm{p} \rightarrow \mathrm{s})
\end{aligned}
$$

\footnotetext{
${ }^{48}$ Speca 2001, 70.

${ }^{49}$ Barnes 1983, 291.

${ }^{50}$ See Ibid 291-292

${ }^{51}$ Hypo syll. II. ix. 7.

${ }^{52}$ Barnes 1983, 292.
} 
But then Philoponus' version $\left(\varepsilon\llcorner\mu \eta \tau 0\right.$ A $\alpha \rho \alpha$ ov $\delta \varepsilon \tau \iota \tau \omega \nu \Gamma),{ }^{53}$ substituting propositions for variables, becomes grammatically incorrect. It also turns out to be an inexplicable use of Boethius' variables as termini. Although this difficulty can be explained by the way Anthony Speca points out that "Boethius also probably did not know the original treatises by Theophrastus, Eudemus, and other early Peripatetics themselves, about which he professed an opinion, nor any original Stoic material... it is possible that Boethius was ignorant or even misleading in his claims about Greek texts on hypothetical syllogistic." ${ }^{54}$ Another way, which is obviously inevitable, is to interpret the variables as terms. In this case, we are faced with grammatical ellipsis.

Thus, in summary, we can say that Alexander develops a definition of logic, setting it up as a mostly categorical syllogistic study with some emphasis on hypothetical techniques. As "the Empire's official Peripatetic philosopher," Alexander founded not only the commentator's logical canon, but also stands at the beginning of the synthesis of Peripatetic and Stoic logic. Strong controversy against the Stoics is a feature of late Peripatetic commentaries on Aristotle. However, Alexander was significantly influenced by Stoic terminology, "even when he uses terms borrowed from Stoicism to express Aristotelian concepts which he then turns against the Stoics. ${ }^{n 5}$ In the same way as Porphyry in the 3-4th centuries AD reconciled Platonism and Aristotelianism, Alexander made a century earlier, creating a logical amalgamation between Peripatetic and Stoic logical traditions.

\section{REFERENCES}

Barnes, J. (1983) Terms And Sentences: Theophrastus On Hypothetical Syllogisms. Oxford. Barnes, J. (2012) Logical Matters: Essays in Ancient Philosophy II. Oxford.

Barnes, J., Bobzien, S., Flannery, K., Ierodiakonou, K., trs (2014) Alexander of Aphrodisias. On Aristotle, Prior Analytics 1.1-7. London.

Bobzien, S. (2002) "The Development of Modus Ponens in Antiquity: From Aristotle to the 2nd Century AD," Phronesis 47 (4), 359-394.

Busse, A., ed. (1891) Ammonius. In Porphyrii Isagogen Sive V Voces, 4.3. Berlin.

Busse, A., ed. (1898) Philoponus. In Aristotelis Categorias Commentarium. Berlin.

Diirr, K. (1951) The Propositional Logic of Boethius. Amsterdam.

Chaniotis, A. (2004) "Epigraphic Evidence for the Philosopher Alexander of Aphrodisias," Bulletin of the Institute of Classical Studies 47, 79-81.

Flannery, K. L. (1995) Ways into the logic of Alexander of Aphrodisias. New York.

\footnotetext{
${ }^{53}$ See Philoponus In A.Pr. 302. 22.

${ }^{54}$ Speca 2001, 69.

${ }^{55}$ Sharples 1987, 1178.
} 


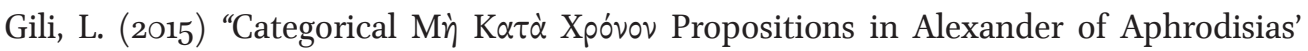
Modal Syllogistic," Apeiron 48 (4), 1-17.

Graeser, A. (1973) Die logischen Fragmenle des Theophrast. Berlin.

Hintikka, J. (1973) Time and Necessity. Studies in Aristotle's Theory of Modality. Oxford.

Kalbfleisch, K., ed. (1907) Simplicius. In Aristotelis Categorias Commentarium. Berlin.

Kalbfleisch, K., ed. (1896) Galenus. Institutio logica. Leipzig.

Karimullah K. (2014) "Al-Farabi on Conditionals," Arabic Sciences and Philosophy 24, 211267 .

Malink, M. (2015) “The Beginnings of Formal Logic: Deduction in Aristotle's Topics vs. Prior Analytics," Phronesis 6o, 267-309.

Mansfeld, J. (1994) Prolegomena. Questions to Be Settled Before the Study of an Author or a Text. London.

Moraux, P. (2001) Der Aristotelismus bei den Griechen. Von Andronikos bis Alexander von Aphrodisias. Berlin.

Mueller, I., ed. (2006) Alexander of Aphrodisias. On Aristotle, Prior Analytics 1.32-46. London.

Sharples, R. W. (1987) "Alexander of Aphrodisias: Scholasticism and Innovation," Aufstieg und Niedergang der Römischen Welt, 2. Band 36.2. Berlin, 1176-1243.

Speca, A (2001) Hypothetical syllogistic and Stoic Logic. Leiden.

Todd, R. (1976) Alexander of Aphrodisias on Stoic Physics. Leiden.

Topchyan, A., ed. (2010) David the Invincible. Commentary on Aristotle's Prior Analytics. Critical Old Armenian Text with an English Translation. Boston.

Wallies, M., ed. (1883) Alexandri in Aristotelis Analyticorum Priorum Librum 1 Commentarium. Commentaria in Aristotelem Graeca 2.1. Berlin.

Wallies, M., ed. (1905) Ioannis Philoponi in Aristotelis Analytica Priora Commentaria. Commentaria in Aristotelem Graeca 13.2. Berlin. 